Portland State University

PDXScholar

\title{
Analysis of Transit Signal Priority Using Archived TriMet Bus Dispatch System Data
}

\author{
Thomas J. Kimpel \\ Portland State University \\ James G. Strathman \\ Portland State University \\ Robert L. Bertini \\ Portland State University \\ Steve Callas \\ TriMet
}

Follow this and additional works at: https://pdxscholar.library.pdx.edu/cus_pubs

Part of the Transportation Commons, and the Urban Studies and Planning Commons Let us know how access to this document benefits you.

\section{Citation Details}

Kimpel, Thomas J.; Strathman, James G.; Bertini, Robert L.; and Callas, Steve, "Analysis of Transit Signal Priority Using Archived TriMet Bus Dispatch System Data" (2005). Center for Urban Studies Publications and Reports. 58.

https://pdxscholar.library.pdx.edu/cus_pubs/58

This Report is brought to you for free and open access. It has been accepted for inclusion in Center for Urban Studies Publications and Reports by an authorized administrator of PDXScholar. Please contact us if we can make this document more accessible: pdxscholar@pdx.edu. 


\title{
Analysis of Transit Signal Priority Using Archived TriMet Bus Dispatch System Data
}

\section{Final Report}

\author{
Thomas J. Kimpel \\ Center for Urban Studies, Portland State University \\ P.O. Box 751, Portland, OR 97207-0751 \\ Phone: 503-725-8207 | Fax: 503-725-8480 | Email: kimpelt@pdx.edu \\ James Strathman \\ Center for Urban Studies, Portland State University \\ P.O. Box 751, Portland, OR 97207-0751 \\ Phone: 503-725-4069 | Fax: 503-725-8480 | Email: strathmanj@pdx.edu \\ Robert L. Bertini \\ Center for Urban Studies, Portland State University \\ P.O. Box 751, Portland, OR 97207-0751 \\ Phone: 503-725-4249 | Fax: 503-725-5950 | Email: bertini@pdx.edu \\ Steve Callas, TriMet \\ 4012 SE 17th Ave., Portland, OR 97202 \\ Phone: 503-962-7502 | Fax: 503-962-3088 | Email: callasc@trimet.org
}

February 2005 


\begin{abstract}
This paper presents findings on changes in bus running times, on-time performance, and excess passenger wait times following implementation of transit signal priority in select bus corridors in the Portland metropolitan region.

Analysis of the effectiveness of transit signal priority is often undertaken using simulation techniques or empirical studies that are either limited in scope and/or data availability. The present research uses an abundance of trip-level data collected from TriMet's Bus Dispatch System. The study focuses on the most common performance measures of interest to both transit operators and passengers. Our study shows that the expected benefits of TSP are not consistent across routes and time periods, nor are they consistent across the various performance measures. We believe that benefits of transit signal priority will accrue only as the result of extensive evaluation and adjustment initial deployment. In most cases, an ongoing performance monitoring and adjustment program should be implemented in order to maximize the benefits of transit signal priority.
\end{abstract}




\section{INTRODUCTION}

A large number of transit properties have implemented transit signal priority (TSP) programs in recent years. The success of TSP in reducing running time delay is widely recognized in the literature, though estimated and actual running time savings vary considerable across studies $(1,2)$. Analysis of the benefits of TSP can be differentiated according to those based on analytical studies, simulation, or empirical analysis using data collected in the field. Analytical studies use mathematical techniques to derive theoretical results. These models can then be tested in more real-world settings using simulation. Simulation studies tend to focus on either a single intersection, or a series of signalized intersections within a corridor. Costs associated with manual data collection efforts may necessitate the use of simulation for quantifying TSP benefits (3). Simulation studies are often undertaken with Empirical studies are often limited with respect to the duration, amount, and type of data collected $(1,2)$. Analysis of the benefits of TSP is often helped by the collection of preliminary baseline data that can be used for comparison purposes following implementation $(4,5,6,7,8)$. Transit properties with automatic vehicle location (AVL) systems in place are much more likely to undertake before and after studies as well as collect data for longer time durations. The majority of empirical studies are "one off" studies in that benefits are measured immediately following TSP implementation and not at subsequent time intervals. Ongoing performance monitoring programs are needed in order to provide feedback for adjusting schedules (9) and signal timing so as to maximize TSP system performance. Limited data availability tends to hinder statistical analysis. Although the majority of TSP studies show positive changes in certain key performance measures following implementation, the real question is whether or not the differences are statistically significant. Previous studies finding statistically significant changes in service reliability and efficiency resulting from TSP implementations include both simulation analysis $(3,10)$ and field studies $(11)$, however, the practice of testing for significant differences are the exception $(4,8)$ rather than the rule.

Our study primarily differs from previous ones in that we undertake analysis of TSP on a large number of route segments comparing operations data derived from the TriMet Bus Dispatch System collected before and after TSP implementation. The TriMet Bus Dispatch System is inimitable among North American transit properties in that detailed operations data are collected for each bus in the system at every stop on a continuous basis. This provides a unique opportunity for comprehensively analyzing changes in bus performance following TSP implementation. The present study analyzes changes in the mean and variance in bus running times, changes in on-time performance (OTP), scheduling benefits, and passenger wait times. The study also includes a regression model looking at the effect of the post TSP implementation period on actual running times.

From a transit standpoint, TSP falls within the domains of service planning, scheduling, performance monitoring, field supervision, and operator training. Prior to implementation, it is important that transit agencies adequately identify the bus routes which could benefit the most from TSP. These routes should be exhibiting poor performance due to operational problems and not because of inadequate scheduling or operator management issues. If buses are consistently early or late, then this would indicate a scheduling or supervision problem. Accurate schedules are critical since they are not exogenous to the process. Portland's TSP system (12) is based on conditional priority whereby late buses beyond a certain delay threshold value request priority until buses are no longer deemed excessively late. Since schedule delay is determined by relating actual to scheduled service, the accuracy of the reference point (the schedule time) has important implications for 1 ) determining whether TSP is even requested in the first place or for how long and 2) monitoring the effectiveness of TSP via performance analysis.

\section{EMPIRICAL ANALYSIS}

\section{Study Characteristics}

Select TriMet bus routes with TSP coverage are represented in the analysis. The characteristics of the analysis segments are presented in Table 1 with Figure 1 showing the locations geographically. Table 1 presents information about the individual route segments including distance, the number of scheduled stops, the number of signalized intersections, the number of priority intersections, and the number of priority intersections with nearside bus stops. We analyze six bus routes broken out by time of day and direction. For peak time periods of operation, we analyze bus performance on radial route segments in the primary direction of travel. Both directions of travel are analyzed on radial routes segments in the midday time period as well as on cross-town route segments in all time periods since there is no primary travel direction. A total of 24 analysis segments are included in the study. 
[Insert Table 1 about here]

[Insert Figure 1 about here]

The 12/112 Barbur Blvd./Sandy Blvd. is a double-spoke, radial through-route connecting the two suburbs of Sherwood and Gresham with Downtown Portland. Each spoke is treated as an individual segment in the analysis. The 109 Powell links Gresham and close in urban neighborhoods with Downtown. The Broadway portion of the 9/109 was excluded from the analysis due to an extended reroute related to light rail construction affecting one of the data collection periods. Route 14 Hawthorne is a high frequency single-spoke radial route serving dense urban neighborhoods in S.E. Portland. Route 72 Killingsworth $/ 82^{\text {nd }}$ Ave. is a high demand, dogleg-shaped cross-town route connecting Clackamas Town Center with the Swan Island industrial area. The 94X is a single-spoke, radial express route operating on a major urban arterial. The $94 \mathrm{X}$ operates on the same street as the 12 Barbur Blvd.

The two samples form a panel in that individual trip-level observations in the pre sample have a corresponding element in the post sample. This helps ensure that any differences in bus running times between the pre and post TSP implementation periods are due to factors other than sample size discrepancies or representative bus trips. Each trip was matched according to a unique identifier consisting of route segment, direction, trip, day of week, and a randomly assigned counter variable. This same approach was employed by the authors in a previous analysis of bus running times (15). Of the 13,868 trip-level observations in the pre sample, we were able to find a direct match with 9,066 observations for a $65.4 \%$ success rate. To control for seasonal effects between the two sampling periods, data were processed for similar months out of the year.

At the time of data collection, signal priority was initialized by means of an emitter if a bus was 90 seconds late or greater. The emitter was turned on and that point and remained on until delay became 30 seconds or less. The present analysis looks at the effectiveness of TSP by comparing bus performance following TSP implementation to baseline conditions prior to "turning the system on". It was not possible to collect information on the number of times a particular bus trip received priority. As such, the present analysis cannot directly measure the effects of TSP on bus performance. A number of confounding factors exist including changes in schedules, operators, signal phasing, and traffic levels to name several, however, these are the conditions that exist in the real world.

\section{Testing for Differences in the Mean and Variance of Running Times}

Transit operations personnel are interested in utilizing limited resources in an efficient manner. Bus running time is a performance measure that is of particular interest to schedulers. Excessive running time variability forces schedulers to add excess recovery/layover time to schedules. As this is non-revenue service, the costs of unreliable service can add up quickly. The data were analyzed to see if there were any changes in the mean and variance of running time between the pre and post TSP implementation periods. A difference in means test for paired samples was used to determine whether changes in mean running times were statistically significant. To test for the difference between two variances, an F-test was employed. The statistical tests were based on the $95 \%$ level of confidence under the null hypotheses that the measures were not statistically different between the two time periods.

Descriptive statistics for mean scheduled running time, mean actual running time, running time variation, and the coefficient of variation of running time are presented in Table 2. All values are presented in minutes. The coefficient of variation provides a useful measure of relative dispersion allowing comparison across analysis segments that vary by the amount of scheduled running time. While scheduled running times have changed slightly between the pre and post TSP implementation periods at the segment level, the differences are relatively small. Over all observations, mean actual running time shows a negligible decrease from 33.2 to 33.1 minutes following TSP implementation. When weighted by the number of trips, run time variation decreases from 13.2 minutes to 12.6 minutes. The weighted coefficient of variation of running time over all segments is the same for both time periods.

Percentage differences for the mean and variance of running times and the results of the means and variances tests are presented in Table 3. The largest percentage reductions in mean running times are associated with Barbur Blvd. in the afternoon peak outbound direction where the 12 and 94X experience double digit reductions. These same two routes also experience reductions in run time variation of approximately 85\%. In contrast, the 112 Sandy Blvd. segment in the morning peak inbound direction and the 12 Barbur Blvd. segment in the midday inbound direction 
experience increases in running time variation greater than $110 \%$. With respect to the coefficient of variation of running time, only $44 \%$ of the segments exhibit a decrease following TSP implementation.

The results of the statistical tests for differences in the mean and variance of run time by time period of operation are presented in Table 4 . Eleven of the 24 analysis segments show a statistically significant difference in mean running time, with eight segments showing significant decreases and three segments showing significant increases. The most striking improvement in mean running times are associated with the afternoon peak time period where all five significant differences are reductions. Routes associated with the morning and midday time periods are evenly split between statistically significant winners and losers, both with few significant differences to begin with. Only eight of the 24 analysis segments show a statistically significant change in run time variability, with five experiencing an actual increase. Only one segment in each time period is associated with a significant reduction in run time variability following TSP implementation.

[Insert Table 2 about here]

[Insert Table 3 about here]

[Insert Table 4 about here]

These results indicate that the changes in bus transit performance following TSP implementation are mixed with respect to the mean, variation, and coefficient of variation of bus running times. The benefits are largely contingent upon the particular segment under consideration and time period of operation. This may be due to physical factors such as route characteristics and system design (e.g., AVL and signal controller logic) as well as operational factors such as excess traffic congestion, delay causing events, changes in passenger demand, operator effects, or inadequate schedules.

\section{Scheduling Implications}

We computed the $50^{\text {th }}, 80^{\text {th }}$, and $95^{\text {th }}$ percentile running times in order to estimate potential savings in scheduled running time and recovery/layover time for each of the analysis segments in each time period. Scheduled running time savings were calculated using Equation 1 and recovery time savings using Equation 2. Both of these formulas were derived from pervious work by Levinson (14) and presented in more detail in Strathman et al. (15). The optimal scheduled running time should be set at slightly less than the mean or median running time so that the majority of operators do not have to kill time to maintain schedule adherence. The optimal recovery time is calculated as the difference between the median and the $95^{\text {th }}$ percentile running time.

SRT Savings $=A R T 50 P_{\text {Post }}-A R T 50 P_{\text {Pre }}$ Equation 1

where:

SRT $=$ Scheduled run time and ART50P $=50^{\text {th }}$ percentile actual running time.

$R /$ L Savings $=\left(A R T 95 P_{\text {Post }}-A R T 50 P_{\text {Post }}\right)-\left(A R T 95 P_{\text {Pre }}-A R T 50 P_{\text {Pre }}\right) \quad$ Equation 2

where:

$\mathrm{R} / \mathrm{L}=$ recovery/layover,

ART95P $=95^{\text {th }}$ percentile actual running time and

ART50P $=50^{\text {th }}$ percentile actual running time. 
The difference in the median running times between the two periods indicates the amount of scheduled running time that can be added to or subtracted from schedules. Table 5 shows which routes serve as the best candidates for adjusting scheduled running time and recovery/layovers time following TSP implementation.

[Insert Table 5 about here]

The majority of scheduled running time savings are associated with the afternoon peak outbound direction where three route segments $(94 \mathrm{X}, 109,112)$ show potential run time savings of approximately one minute or more. In the morning time period, the results indicate that six of the seven route segments might need additional running time added to schedules. In contrast, in the afternoon peak time period, six of the seven of seven analysis segments show that running time may need to be removed from schedules. With respect to savings in recovery/layover time, we find the largest potential savings associated with the 12 and 94X segments in the afternoon peak time period in the outbound direction of travel. Within each time period, the results are largely mixed with certain segments showing potential savings in recovery/layover times and others showing that potential additions are warranted. Overall, when weighted by the number of trips, we find slight potential savings in both scheduled run time (5.4 seconds) and recovery/layover time (7.2 seconds).

Much of the proceeding information can be displayed in a run time delay distribution graph. Run time delay is a measure of actual run time minus scheduled run time. Figure 2 illustrates the run time delay distribution for bus trips on the 12 Barbur Blvd. in the afternoon peak outbound direction. This route segment was chosen because it is representative of the potential savings in run times that can be expected following TSP implementation. Relative to the baseline time period, the run time delay distribution has narrowed considerably largely due to reductions in the number of excessive delays.

[Insert Figure 2 about here]

\section{Passenger Benefits of TSP}

The expected benefits to passengers from TSP include improved OTP, reductions in wait time, and shorter invehicle times. We focus on the OTP and wait time savings in this analysis since we lack information on passenger origins and destinations for computing an aggregate measure of in-vehicle time. TriMet defines a bus as "on-time" if it departs a predetermined location between one minute early and 5 minutes late. OTP is typically measured at time points. For this analysis, we measure OTP at the terminus of each analysis segment since the benefits of signal priority should be greatest at this location. A comparison of OTP by time of day before and after TSP implementation is presented in Table 6. Over all analysis segments, OTP actually becomes worse, exhibiting a 5.0\% decrease following TSP implementation. This decrease is largely due the percentage of trips in the on-time category (65.9\% pre versus $62.6 \%$ post) shifting to early ( $22.2 \%$ pre versus $25.7 \%$ post) as the percentage of late departures remains largely unchanged (11.9\% pre versus $11.7 \%$ post). Within each time period, the results are mixed with some routes exhibiting improved OTP and others becoming worse. The largest percent reductions in OTP are associated with the $94 \mathrm{X}$ and 112 inbound in the morning peak, the 14 inbound in the midday time period, and the 12 and 94X outbound during the afternoon peak. The 12 inbound in the morning and afternoon peak periods exhibits the largest improvements in OTP, largely due to a shift in the number of early bus trips towards on-time. These findings indicate that schedules should be revisited following TSP implementation.

[Insert Table 6 about here]

An important transit service performance measure of relevance to passengers is excess wait time which is a stoplevel measure that takes into account the mean and variance of headways. As headway variance increases, departure times at stops become less predictable, forcing passengers to compensate by arriving at locations much earlier in time. In theory, TSP should reduce headway variability as late buses are granted priority and can therefore adhere more closely to schedule. For the present study, headways were measured at the maximum load point in order to be consistent with internal TriMet reporting practices for calculating excess wait time. The analysis uses the same matched pair approach described earlier except that it involved the use of a stop-level dataset rather than a trip-level one. We were able to match 7,348 observations between the pre and post time periods for a success rate of $78.9 \%$. 
Table 7 shows the results of the headway and wait time analyses. Generally speaking, we find that both the mean and the variance of headways increase relative to the baseline period. Seventeen of the 24 analysis segments experience an increase in mean headway compared to the baseline period. Twenty-one of the 24 analysis segments experience an increase in headway variation. When weighted by the number of trips, we find that the mean and variation of actual headway increases in all time periods relative to the baseline period as well as over all of the analysis segments (34.4\% and 3.1\% respectively).

The formula for excess wait time presented in Equation 3 is a modification of earlier formula presented by Hounsell and McLeod (16) and discussed in more detail in Strathman et al. (13).

$$
E W=((H W R V /(2 * H W R X)) / 100) * H W A X
$$

\author{
where: \\ HWRV is the variance of the headway ratio [(actual HW/scheduled HW) * 100], \\ HWRX is the mean of the headway ratio and \\ HWAX is the average actual headway.
}

Of the 24 analysis segments, only seven show a decrease in excess wait time. The largest percentage reductions in excess wait time following TSP implementation are associated with the $94 \mathrm{X}$ in the morning peak inbound direction (-55.9\%) and the 112 afternoon peak in the outbound direction (-60.4\%). The largest percentage increases in excess wait time are associated with the 12 inbound in the morning peak (117.1\%) and 12 outbound in the midday time period (93.1\%). Over all of the analysis segments, we find a $-2.8 \%$ reduction in excess wait time for the period following TSP implementation. No clear pattern emerges with respect to changes in excess wait time within each time period. The results are largely segment and time of day specific.

[Insert Table 7 about here]

\title{
Regression Analysis
}

One objective of the present study is to analyze the determinants of bus running time at the route segment level of analysis. We include a regression analysis to better understand the determinants of running time and to measure the effect of the post TSP implementation data collection period on bus running time. The data used for the regression model is the same as that used for the running time, OTP, and schedule savings components except that the data for each implementation period are "stacked" rather than "side-by-side". The regression model contains 18,132 observations.

A review of the literature $(13,15,17,18)$ finds that running time is related to route characteristics such as distance or the number of stops, the amount of scheduled service, passenger demand variation, bus spacing irregularities, operator behavior, non-recurring delays, time period of operation, and in the context of the present analysis, the effect of the post-implementation period. A description of the variables used in the regression analysis is presented in Table 8.

\section{[Insert Table 8 about here]}

The dependent variable is actual run time (RTA) in minutes. We use the number of actual stops (STOPS) as a proxy for passenger boarding and alighting activity which encompasses dwell time and delays associated with acceleration and deceleration. The stops variable also proxies for bus interaction effects (headway delay) since late buses will tend to stop more often while early buses tend to stop less often. The expected sign on the coefficient for actual stops is positive since actual run time should increase with more stopping activity. Scheduled running time (SRT) is included in the model to control for the effects of distance as well as bus operating conditions such as traffic congestion. The expected sign on the coefficient is positive with the magnitude of the coefficient expected to be large relative to other variables given the authors past experience with trip level models of actual run time. Delay causing events are addressed through use of a variable representing the actual number of lift operations (LIFT) over the segment. This variable is also expected to contribute to running time. It is posited that dummy variable for the post-implementation period (PERIOD) will have a negative effect on bus running time. This variable will pick up 
the effect of TSP along with other exogenous factors that may have changed between the pre and post TSP implementation periods. Time period of operation and direction of travel serve to proxy for the effects of traffic. Relative to the midday time period, the morning peak period dummy variable is expected to have a negative sign and the afternoon peak a positive sign. Operator experience as measured by years of service (EXPER) is posited to be negatively associated with running time as experienced operators should be able to more adequately respond to situational disturbances relative to inexperienced operators. Operator behavior can adversely impact running time through such actions as departing late from the origin terminal (LTETRM). We expect bus running times to be positively associated with late departures from trip origins.

Descriptive statistics for the regression data are presented in Table 9. The average running time over all trips is 33.2 minutes with scheduled running time being 31.9 minutes. The mean number of actual stops is 26.1 stops per segment per trip with approximately one in five trips being associated with a lift operation. The average number of years of operator experience is 11.8 years. Buses appear to be departing late from origin terminals by approximately 1.4 minutes on average. The descriptive statistics also show that roughly $16 \%$ the trips are associated with the morning peak time period in the inbound direction and $17 \%$ of the trips associated with the afternoon peak time period in the outbound direction.

[Insert Table 9 about here]

The results of the regression model are presented in Table 10. Estimates have been converted to seconds in the last column for ease of interpretation. The amount of variance explained by the model is $97.1 \%$. In the present model, approximately 53.3 seconds of each minute of actual running time is controlled for by scheduled running time, holding all other variables at their mean values. The estimated coefficient for the number of actual stops is statistically significant and positive. The magnitude appears reasonable given that each actual stop is shown to contribute 12.1 seconds to running time. The lift operation variable is statistically significant and positive. The estimated effect is 65.1 seconds of delay per lift operation. Operator experience is shown to be significant and negatively associated with bus running time, with each year of service attributable to a 1.7 second reduction in running time. The late departure terminal variable is statistically significant and negative but has only a minor effect on actual run time. This finding is perhaps the result of operators knowing that they can make up a portion of origin delay elsewhere along the route. The time period of operation variables are consistent with expected trends. The morning peak time period is associated with a 44.4 second reduction in bus running time and the afternoon peak time period is associated with a 70.4 second increase relative to the midday time period. The dummy variable for the period following TSP implementation is statistically significant and negative, with the post implementation period associated with a reduction in run time of 14.2 seconds per trip holding all other variables at their mean values. In truthfulness, we cannot state that this reduction is solely due to TSP as other factors are at least partially responsible for the decrease.

[Insert Table 10 about here]

\section{DISCUSSION}

The present study utilizes a large amount of operations data collected from the TriMet Bus Dispatch System. The majority of transit properties implementing TSP do not have the capability to collect and analyze operations data for each bus in the system at the stop level since their AVL systems tend to be based on poll data. Our study provides a comprehensive analysis of changes in bus performance from the perspective of operators and passengers by analyzing data collected before and after TSP implementation.

One of our most important findings is that the changes in bus performance following TSP implementation are not consistent across time periods, routes, or performance measures. This is summarized in Tables 11-13. Table 11 provides a summary of the analysis segments according to the various performance measures by time period. A positive signs means that bus performance improved in the ideal direction of a particular measure. For example, an increase in OTP is desirable as well as a decrease in running time variation. For the 12 Barbur Blvd. segment in the outbound direction in the afternoon peak time period, we find improvements in mean running time, running time variation, potential savings in recovery/layover times. OTP also improved, although the number of early arrivals 
increased sharply, while headway variation and excess wait time became worse. Of the 24 analysis segments, only the 112 Sandy Blvd. outbound in the midday time period exhibits an improvement across all of the performance measures. In looking at the totals, one might conclude that bus transit performance has improved over the majority of the performance measures, however, the results are mixed when looking at individual segments by time of day.

Also of note is the wide variation in bus transit performance when each route segment is aggregated over all time periods, irrespective of the direction of travel. Table 12 shows the percent of segments exhibiting improvements in performance when aggregated by route over all time periods. For example, four analysis segments are summarized for the 12 Barbur. Blvd.- the 12 inbound in the morning peak, both directions in the midday time period, and the 12 outbound in the afternoon peak. Of the four segments, two (50\%) show improvements in mean actual running time, running time variation, scheduled running time savings, recovery/layover time savings, and mean actual headway. Three of the four segments show an improvement in OTP and zero segments show an improvement in headway variability and excess wait time. The $94 \mathrm{X}$ and the 112 show the greatest improvement over all of the performance measures with the 14 and the 72 showing the least improvement. We find that less than $50 \%$ of the route segments experience improved performance relative to the baseline period across all of the measures.

Table 13 shows the percent of segments exhibiting improvements in performance when aggregated by time period. Seven analysis segments are represented in the morning peak time period. Only one performance measure, OTP, shows an improvement greater than 50\% relative to the baseline period. Of note is that the segments in the afternoon peak time period perform better across each of the performance measures relative to the midday and morning peak time periods with the exception of OTP in the morning peak. In the afternoon peak, $85.7 \%$ of the segments show potential scheduled run time savings and $71.4 \%$ show savings in mean actual run time. The totals in Table 13 are the same as those for Table 12.

So what do our findings mean for traffic engineers and transit professionals? The answer partially depends on how one chooses to interpret the results. The present study involves measuring transit performance in select corridors following TSP implementation relative to the pre-implementation period. The study does not attempt to ascertain whether changes in bus transit service reliability are the direct result of TSP. Given a complex operating environment, the variables most likely to likely to influence the results include changes in passenger demand, traffic levels and bus operators; stop relocations/modifications; schedule revisions; signal timing adjustments; and TSP. We believe that the present study adequately captures real world conditions since the various parts of the system change over time. Besides better scheduling and management of operators, a number of potential improvements exist. Since this study was first undertaken, TriMet has since lowered the delay threshold for priority requests to 30 seconds of schedule delay or greater - the reasoning being that more buses will receive priority with a lower delay threshold. We believe that the agency should experiment with altering the delay threshold for priority requests according to the specific corridor, direction, and time of day in order to more adequately respond to spatial and temporal variations in operating conditions. Besides queue jumps which exist at a few select intersections, other priority treatments such as bus only phases or elimination of phase skipping could be considered. Discussions are presently underway to add more "logic" to the existing system by supplementing the AVL information on an intersection by intersection basis. For example, priority requests at intersections with near-side bus stops could be deferred until the bus has completed serving a particular stop (i.e., point activation based on AVL distance). It is clear that much work still needs to be done.

We believe that TSP projects should be implemented with caution and recommend the following plan of action:

1. Select candidate bus routes based on identification of operational problems, not scheduling or personnel problems.

2. Perform a baseline analysis so as to have a reference case for comparison following implementation.

3. Undertake regular performance monitoring following TSP implementation to identify problems warranting additional scrutiny.

4. Be willing to experiment by adjusting schedules, emitter activation thresholds, signal controller/AVL logic etc. with the goal of improving the performance of the system over time.

Automatically collected, stop-level data such as that generated by the TriMet Bus Dispatch System can readily provide the kinds of information needed to address each of the above items. 


\section{CONCLUSIONS}

We empirically analyzed the effects of TSP implementation from both the perspective of the transit operators as well as passengers. The study included a statistical analysis of the mean and variance of bus running times. Generally speaking, we found that the primary benefits of TSP on mean running time are limited to the afternoon peak time period in the primary direction of travel. For the morning peak and afternoon time periods, the results were more ambiguous. While potential overall savings were found with respect to scheduled running times and

recovery/layover times, the results are mixed when looking at individual routes by direction and time of day. The same holds true for analysis of excess wait time. The mean and variance of headways became much worse relative to the baseline period. In analyzing OTP, we found that performance decreased overall as bus trips tended to shift from being either on-time or late towards being early. The results of the regression analysis shows that there was a statistically significant improvement in bus running times for the period following implementation of TSP. We believe that a considerable amount of work needs to be done with respect to signal priority programs before the expected benefits of TSP are fully realized. 


\section{REFERENCES}

1. ITS America. An Overview of Transit Signal Priority. Prepared by Advanced Traffic Management Systems Committee and Advanced Public Transportation Systems Committee, ITS America, Washington, D.C., 2002

2. Collura, J., Rakha, H, and J. Gifford. Guidelines for the Planning and Deployment of Emergency Vehicle Preemption and Transit Priority Strategies. Prepared by the Virginia Tech Transportation Institute and George Mason University School of Public Policy, 2003

3. Dale, J. J., Atherley, R. J., Bauer, T., and L. Madsen. Transit Signal Priority Impact Assessment MethodologyGreater Reliance on Simulation. Presented at 78th Annual Meeting of the Transportation Research Board, Washington, D.C. 1999.

4. King County Department of Transportation. An Evaluation of Transit Signal Priority in Aurora Avenue North, Transit Speed and Reliability Program, King County Department of Transportation, 2002.

5. Crout, D. Transit Signal Priority Evaluation. Presented at the ITS America 13th Annual Meeting and Exposition, Minneapolis, MN, 2003.

6. Lewis, V. Bus Priority Study: Tualatin Valley Highway. Tri-Met, Portland, OR, 1996.

7. Hunter-Zaworksi, K., Kloos, W. and A. Danaher. Bus Priority at Traffic Signals in Portland: The Powell Boulevard Pilot Project. In Transportation Research Record 1503, TRB, National Research Council, Washington, D.C., 1994, pp.29-33.

8. Los Angeles County Metropolitan Transportation Authority. Los Angeles Metro Rapid Demonstration Program, Los Angeles County Metropolitan Transportation Authority, 2001.

9. Furth, P. G. Synthesis of Transit Practice 34: Data Analysis for Bus Planning and Monitoring, TRB, National Research Council, Washington, DC., 2000.

10. Chang, D., Collura, J., Dion, F., and H. Rakha. Evaluation of Service Reliability Impacts of Traffic Signal Priority Strategies for Bus Transit. Center for ITS Implementation Research, U.S. Department of Transportation, 2003.

11. Furth, P. G. and T. Mueller. Conditional Bus Priority at Signalized Intersections. Presented at 79th Annual Meeting of the Transportation Research Board. Washington, D.C., 2000.

12. Koonce, P., Kloos, B., and S. Callas. Bus Priority at Traffic Signals in Portland- Version 2.0: The Streamline Project. Compendium of Technical Papers, 2002 ITE Annual Meeting, Philadelphia, PA, 2002.

13. Strathman, J. G., K. Dueker, K. J., Kimpel, T. J., Gerhart, R., Turner, K., Taylor, P., Callas, S., and D. Griffin. Service Reliability Impacts of Computer-Aided Dispatching and Automatic Vehicle Location Technology: A Tri-Met Case Study. Transportation Quarterly, Vol. 54, 2000, pp. 85-102.

14. Levinson, H. S. NCHRP Synthesis of Transit Practice 15: Supervision Strategies for Improved Reliability of Bus Routes, TRB, National Research Council, Washington, DC., 1991.

15. Strathman, J., Dueker, K., Kimpel, T., Gerhart, R., \& S. Callas. Evaluation of Transit Operations: Data Applications of Tri-Met's Automated Bus Dispatch System. Transportation, Vol. 29, 2002, pp. 321-345.

16. Hounsell, N. and F. McLeod. 1998. AVL Implementation Application and Benefits in the U.K. Paper presented the 77th Annual Meeting of the Transportation Research Board, TRB, National Research Council, Washington, D.C., January 11-15. 
17. Abkowitz, M. and J. Tozzi. Research Contributions to Managing Transit Service Reliability. Journal of Advanced Transportation, Vol. 21, 1987, pp. 47-65.

18. Sterman, B. and J. Schofer. Factors Affecting Reliability of Urban Bus Services. Transportation Engineering Journal, Vol. 102, 1976, pp. 147-159. 


\section{LIST OF TABLES}

1. TABLE 1 Analysis Segments

2. TABLE 2 Descriptive Statistics

3. TABLE 3 Running Time Analysis

4. TABLE 4 Running Time Analysis Summary

5. TABLE 5 Scheduling Benefits of TSP

6. TABLE 6 On-Time Performance Analysis

7. TABLE 7 Headway Analysis

8. TABLE 8 Regression Analysis- Variable Description

9. TABLE 9 Regression Analysis- Descriptive Statistics

10. TABLE 10 Regression Analysis- Results

11. TABLE 11 Summary: Performance Measures by Analysis Segment

12. TABLE 12 Summary: Percentage of Segments Showing Improvements by Route

13. TABLE 13 Summary: Percentage of Segments Showing Improvements by Time of Day

\section{LIST OF FIGURES}

14. FIGURE 1 Study Area Map

15. FIGURE 2 Running Time Distribution Example 
TABLE 1 Analysis Segments

\begin{tabular}{llccccc} 
Segment $^{\mathrm{a}}$ & Name & $\begin{array}{c}\text { Dist. } \\
(\mathrm{miles})\end{array}$ & $\begin{array}{c}\text { Bus } \\
\text { Stops }\end{array}$ & $\begin{array}{c}\text { Traffic } \\
\text { Signals }\end{array}$ & $\begin{array}{c}\text { Priority } \\
\text { Signals }\end{array}$ & $\begin{array}{c}\text { Nearside } \\
\text { Stops }\end{array}$ \\
\hline $12-0$ & Barbur Blvd. & 6.2 & 29 & 13 & 13 & 5 \\
$12-1$ & Barbur Blvd. & 6.1 & 30 & 13 & 13 & 6 \\
$14-0$ & Hawthorne & 5.9 & 46 & 25 & 18 & 5 \\
$14-1$ & Hawthorne & 5.9 & 44 & 25 & 18 & 14 \\
$72-\mathrm{N} / \mathrm{W}$ & 82 $^{\text {nd }}$ Ave./Killingsworth & 13.1 & 95 & 47 & 32 & 17 \\
$72-\mathrm{S}$ S & 82 $^{\text {nd }}$ Ave./Killingsworth & 13.0 & 95 & 46 & 32 & 20 \\
$94 \mathrm{X}-0$ & Sherwood-Pacific Hwy. & 8.4 & 5 & 19 & 13 & 1 \\
$94 \mathrm{X}-1$ & Sherwood-Pacific Hwy. & 8.2 & 6 & 19 & 13 & 2 \\
$109-0$ & Powell & 4.0 & 30 & 17 & 13 & 3 \\
$109-1$ & Powell & 4.0 & 30 & 17 & 13 & 3 \\
$112-0$ & Sandy Blvd. & 5.2 & 36 & 28 & 19 & 7 \\
$112-1$ & Sandy Blvd. & 5.2 & 37 & 28 & 19 & 14 \\
\hline
\end{tabular}

(a) Segment naming convention is route-direction (e.g., 12-0). For radial route segments, $0=$ outbound or $1=$ inbound. For cross-town routes segments, the actual direction is used. 
TABLE 2 Descriptive Statistics

\begin{tabular}{|c|c|c|c|c|c|c|c|c|c|c|}
\hline \multirow[b]{2}{*}{ TOD } & \multirow[b]{2}{*}{ Segment } & \multirow[b]{2}{*}{$\mathrm{N}$} & \multicolumn{2}{|c|}{$\begin{array}{l}\text { Mean Scheduled } \\
\text { Run Time (min.) }\end{array}$} & \multicolumn{2}{|c|}{$\begin{array}{c}\text { Mean Actual } \\
\text { Run Time (min.) }\end{array}$} & \multicolumn{2}{|c|}{$\begin{array}{c}\text { Var. Actual } \\
\text { Run Time (min.) }\end{array}$} & \multicolumn{2}{|c|}{$\begin{array}{c}\text { C.V. }{ }^{a} \text { Actual } \\
\text { Run Time (min.) }\end{array}$} \\
\hline & & & Pre & Post & Pre & Post & Pre & Post & Pre & Post \\
\hline \multirow[t]{7}{*}{ A.M. } & $12-1$ & 136 & 22.1 & 21.8 & 20.0 & 20.2 & 6.3 & 3.6 & 12.5 & 9.4 \\
\hline & $14-1$ & 350 & 31.3 & 31.3 & 30.2 & 29.9 & 5.1 & 4.2 & 7.5 & 6.8 \\
\hline & 72-N/W & 203 & 51.8 & 51.8 & 55.4 & 54.4 & 13.0 & 12.1 & 6.5 & 6.4 \\
\hline & 72-E/S & 194 & 54.1 & 54.1 & 55.2 & 55.6 & 6.8 & 12.2 & 4.7 & 6.3 \\
\hline & $94 X-1$ & 138 & 20.8 & 22.8 & 22.7 & 22.7 & 9.5 & 8.2 & 13.6 & 12.6 \\
\hline & $109-1$ & 218 & 18.3 & 18.3 & 19.0 & 19.4 & 3.5 & 4.8 & 9.9 & 11.2 \\
\hline & $112-1$ & 177 & 24.5 & 25.5 & 25.5 & 25.9 & 4.1 & 8.8 & 7.9 & 11.4 \\
\hline \multirow[t]{10}{*}{ Midday } & $12-0$ & 538 & 20.2 & 20.3 & 19.3 & 19.1 & 7.7 & 8.5 & 14.4 & 15.3 \\
\hline & $12-1$ & 548 & 20.4 & 19.6 & 17.8 & 17.8 & 3.0 & 6.3 & 9.7 & 14.1 \\
\hline & $14-0$ & 658 & 26.8 & 26.8 & 28.6 & 28.8 & 14.1 & 19.4 & 13.1 & 15.3 \\
\hline & $14-1$ & 651 & 29.3 & 29.6 & 29.6 & 29.3 & 6.1 & 5.5 & 8.3 & 8.0 \\
\hline & 72-N/W & 800 & 55.6 & 55.6 & 59.4 & 59.4 & 32.8 & 31.4 & 9.6 & 9.4 \\
\hline & 72-E/S & 776 & 57.5 & 57.5 & 60.0 & 60.5 & 23.8 & 26.9 & 8.1 & 8.6 \\
\hline & $109-0$ & 538 & 16.6 & 16.5 & 18.2 & 18.0 & 6.4 & 6.7 & 13.9 & 14.4 \\
\hline & $109-1$ & 539 & 17.2 & 17.2 & 18.4 & 18.5 & 5.0 & 4.2 & 12.2 & 11.1 \\
\hline & $112-0$ & 517 & 21.2 & 21.1 & 22.8 & 22.5 & 8.9 & 7.7 & 13.1 & 12.4 \\
\hline & $112-1$ & 551 & 22.0 & 22.6 & 22.9 & 23.2 & 3.9 & 5.2 & 8.6 & 9.8 \\
\hline \multirow[t]{7}{*}{ P.M. } & $12-0$ & 156 & 24.7 & 24.7 & 25.6 & 22.6 & 49.0 & 6.6 & 27.4 & 11.4 \\
\hline & $14-0$ & 373 & 30.0 & 30.0 & 32.1 & 32.4 & 7.1 & 11.3 & 8.3 & 10.4 \\
\hline & 72-N/W & 243 & 59.1 & 59.1 & 63.0 & 62.3 & 15.9 & 12.5 & 6.3 & 5.7 \\
\hline & 72-E/S & 211 & 58.8 & 58.8 & 62.9 & 63.3 & 24.1 & 38.8 & 7.8 & 9.8 \\
\hline & $94 \mathrm{X}-0$ & 198 & 18.8 & 20.4 & 24.5 & 20.3 & 59.7 & 8.8 & 31.6 & 14.6 \\
\hline & $109-0$ & 143 & 20.1 & 18.7 & 21.4 & 20.2 & 5.4 & 5.6 & 10.9 & 11.7 \\
\hline & $112-0$ & 210 & 23.3 & 23.1 & 25.8 & 24.1 & 7.2 & 6.6 & 10.4 & 10.7 \\
\hline Total & All & 9,066 & 31.8 & 31.9 & 33.2 & 33.1 & $13.2^{b}$ & $12.6^{b}$ & $10.9^{b}$ & $10.9^{b}$ \\
\hline
\end{tabular}

(a) C.V. = coefficient of variation

(b) Denotes weighted total (weighted by the number of trips for each segment in time period) 
TABLE 3 Running Time Analysis

\begin{tabular}{|c|c|c|c|c|c|c|c|}
\hline \multirow[b]{2}{*}{ TOD } & \multirow[b]{2}{*}{ Segment } & \multirow[b]{2}{*}{$\mathrm{N}$} & \multicolumn{2}{|c|}{$\begin{array}{l}\text { Mean Actual } \\
\text { Run Time } \\
\text { (min.) }\end{array}$} & \multicolumn{2}{|c|}{$\begin{array}{c}\text { Var. Actual } \\
\text { Run Time } \\
\text { (min.) }\end{array}$} & \multirow{2}{*}{$\begin{array}{l}\text { C.V. a Actual } \\
\text { Run Time } \\
\text { (min.) } \\
\text { \% Diff. }\end{array}$} \\
\hline & & & \% Diff. & $\begin{array}{c}\text { Sig. } \\
\text { (t-test) }\end{array}$ & \% Diff. & $\begin{array}{c}\text { Sig. } \\
\text { (F-test) }\end{array}$ & \\
\hline \multirow{7}{*}{ A.M. } & $12-1$ & 136 & 0.9 & . & -42.2 & $* *$ & -24.6 \\
\hline & $14-1$ & 350 & -0.8 & . & -18.3 & . & -8.8 \\
\hline & 72-N/W & 203 & -1.9 & $* *$ & -7.6 & . & -2.1 \\
\hline & 72-E/S & 194 & 0.9 & . & 77.7 & $* *$ & 32.2 \\
\hline & $94 X-1$ & 138 & 0.2 & . & -13.3 & . & -7.1 \\
\hline & $109-1$ & 218 & 2.2 & ** & 35.6 & . & 13.9 \\
\hline & $112-1$ & 177 & 1.9 & . & 116.8 & $* *$ & 44.5 \\
\hline \multirow[t]{10}{*}{ Midday } & $12-0$ & 538 & -1.0 & . & 10.5 & & 6.2 \\
\hline & $12-1$ & 548 & 0.1 & . & 111.6 & $* *$ & 45.3 \\
\hline & $14-0$ & 658 & 0.6 & . & 37.3 & ** & 16.5 \\
\hline & $14-1$ & 651 & -1.3 & ** & -10.1 & . & -3.9 \\
\hline & $72-\mathrm{N} / \mathrm{W}$ & 800 & 0.0 & . & -4.2 & . & -2.1 \\
\hline & 72-E/S & 776 & 0.7 & ** & 12.7 & . & 5.4 \\
\hline & $109-0$ & 538 & -0.9 & . & 5.4 & . & 3.6 \\
\hline & $109-1$ & 539 & 0.6 & . & -16.1 & $* *$ & -9.0 \\
\hline & $112-0$ & 517 & -1.4 & $* *$ & -13.3 & & -5.6 \\
\hline & $112-1$ & 551 & 1.3 & $* *$ & 32.8 & $* *$ & 13.7 \\
\hline \multirow[t]{7}{*}{ P.M. } & $12-0$ & 156 & -11.8 & $* *$ & -86.4 & . & -58.2 \\
\hline & $14-0$ & 373 & 0.9 & . & 59.6 & . & 25.2 \\
\hline & 72-N/W & 243 & -1.1 & $* *$ & -21.4 & . & -10.3 \\
\hline & 72-E/S & 211 & 0.7 & . & 60.8 & $* *$ & 26.0 \\
\hline & $94 X-0$ & 198 & -17.0 & $* *$ & -85.3 & $* *$ & -53.8 \\
\hline & $109-0$ & 143 & -5.6 & ** & 2.2 & . & 7.1 \\
\hline & $112-0$ & 210 & -6.4 & $* *$ & -8.1 & . & 2.5 \\
\hline Total & & 9,066 & -0.6 & $* *$ & $-4.5^{\mathrm{b}}$ & & $0.0^{\mathrm{b}}$ \\
\hline
\end{tabular}

(a) C.V. = coefficient of variation

(b) Based on weighted totals

${ }^{* *}$ ) Denotes statistically significant difference at the $95 \%$ level of confidence 
TABLE 4 Running Time Analysis Summary

\begin{tabular}{lc|cc|c} 
& $\begin{array}{c}\text { Mean Actual } \\
\text { Running Time } \\
\text { TOD }\end{array}$ & $\begin{array}{c}\text { Var. Actual } \\
\text { Running Time } \\
\text { Lower }\end{array}$ & Higher & Higher \\
\hline A.M. & 1 & 1 & 1 & 1 \\
Midday & 2 & 2 & 1 & 3 \\
P.M. & 5 & 0 & 1 & 1 \\
\hline Total & 8 & 3 & 3 & 5 \\
\hline
\end{tabular}


TABLE 5 Scheduling Benefits of TSP

\begin{tabular}{|c|c|c|c|c|c|c|c|c|c|}
\hline \multirow[b]{2}{*}{ TOD } & \multirow[b]{2}{*}{ Segment } & \multicolumn{3}{|c|}{ Pre (min.) } & \multicolumn{3}{|c|}{ Post (min.) } & \multirow{2}{*}{$\begin{array}{l}\text { Sched. Run } \\
\text { Time Savings } \\
\text { (min.) }\end{array}$} & \multirow{2}{*}{$\begin{array}{c}\text { Recovery } \\
\text { Time Savings } \\
\text { (min.) }\end{array}$} \\
\hline & & 50th & 80th & 95th & 50th & 80th & 95th & & \\
\hline \multirow[t]{7}{*}{ A.M. } & $12-1$ & 19.7 & 21.4 & 22.9 & 20.3 & 21.7 & 23.2 & 0.60 & -0.26 \\
\hline & $14-1$ & 29.8 & 31.2 & 32.8 & 30.0 & 31.3 & 33.3 & 0.17 & 0.30 \\
\hline & 72-N/W & 54.7 & 58.8 & 62.1 & 54.0 & 56.9 & 61.1 & -0.67 & -0.33 \\
\hline & 72-E/S & 54.8 & 57.0 & 60.3 & 55.2 & 58.0 & 61.6 & 0.42 & 0.92 \\
\hline & $94 X-1$ & 21.9 & 23.9 & 29.4 & 22.3 & 25.2 & 28.2 & 0.38 & -1.59 \\
\hline & $109-1$ & 18.9 & 20.4 & 22.4 & 19.4 & 21.2 & 23.1 & 0.45 & 0.23 \\
\hline & $112-1$ & 25.2 & 27.0 & 29.1 & 25.3 & 27.8 & 31.5 & 0.10 & 2.27 \\
\hline \multirow[t]{10}{*}{ Midday } & $12-0$ & 18.9 & 21.2 & 23.5 & 18.6 & 21.1 & 23.8 & -0.30 & 0.60 \\
\hline & $12-1$ & 17.7 & 19.3 & 20.7 & 17.7 & 19.1 & 20.9 & 0.03 & 0.11 \\
\hline & $14-0$ & 28.4 & 31.7 & 35.1 & 28.4 & 31.7 & 36.1 & 0.05 & 0.97 \\
\hline & $14-1$ & 29.3 & 31.2 & 33.4 & 28.8 & 30.9 & 33.8 & -0.53 & 0.87 \\
\hline & 72-N/W & 58.6 & 64.5 & 68.7 & 59.2 & 64.3 & 68.3 & 0.57 & -0.89 \\
\hline & 72-E/S & 59.8 & 63.8 & 68.7 & 59.9 & 64.6 & 69.1 & 0.07 & 0.39 \\
\hline & $109-0$ & 18.0 & 20.4 & 22.4 & 17.8 & 19.9 & 23.0 & -0.15 & 0.72 \\
\hline & $109-1$ & 18.2 & 20.2 & 22.4 & 18.3 & 20.1 & 22.1 & 0.17 & -0.52 \\
\hline & $112-0$ & 22.8 & 25.1 & 27.9 & 22.4 & 24.7 & 27.3 & -0.40 & -0.15 \\
\hline & $112-1$ & 22.7 & 24.5 & 26.3 & 23.0 & 25.0 & 27.5 & 0.23 & 0.90 \\
\hline \multirow[t]{7}{*}{ P.M. } & $12-0$ & 23.0 & 30.8 & 38.1 & 22.2 & 24.5 & 27.7 & -0.80 & -9.61 \\
\hline & $14-0$ & 31.8 & 33.9 & 36.7 & 31.7 & 34.5 & 38.6 & -0.13 & 2.02 \\
\hline & 72-N/W & 62.7 & 66.0 & 69.5 & 62.1 & 65.3 & 68.9 & -0.53 & -0.08 \\
\hline & 72-E/S & 62.1 & 66.7 & 70.8 & 62.8 & 67.6 & 74.5 & 0.73 & 3.03 \\
\hline & $94 X-0$ & 21.4 & 28.6 & 42.1 & 19.7 & 21.8 & 26.2 & -1.75 & -14.19 \\
\hline & $109-0$ & 21.3 & 22.8 & 25.5 & 19.8 & 21.4 & 24.1 & -1.47 & 0.11 \\
\hline & $112-0$ & 25.5 & 28.2 & 30.7 & 24.1 & 26.2 & 28.0 & -1.43 & -1.30 \\
\hline Total & All & • & & 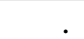 & & & & $-0.09^{\mathrm{a}}$ & $-0.12^{\mathrm{a}}$ \\
\hline
\end{tabular}

(a) Denotes weighted total (weighted by the number of trips for each segment in time period) 
TABLE 6 On-Time Performance Analysis

\begin{tabular}{|c|c|c|c|c|c|c|c|c|}
\hline \multirow[b]{2}{*}{ TOD } & \multirow[b]{2}{*}{ Segment } & \multicolumn{3}{|c|}{ Pre (\% of trips) } & \multicolumn{2}{|c|}{ Post (\% of trips) } & & \multirow{2}{*}{$\begin{array}{l}\text { \% Diff. } \\
\text { On-Time }\end{array}$} \\
\hline & & Early & On-Time & Late & Early & On-Time & Late & \\
\hline \multirow[t]{7}{*}{ A.M. } & $12-1$ & 72.1 & 25.7 & 2.2 & 62.5 & 36.8 & 0.7 & 42.9 \\
\hline & $14-1$ & 60.3 & 39.1 & 0.6 & 59.1 & 40.9 & 0.0 & 4.4 \\
\hline & 72-N/W & 5.9 & 65.0 & 29.1 & 10.8 & 70.0 & 19.2 & 7.6 \\
\hline & 72-E/S & 20.1 & 69.6 & 10.3 & 19.1 & 64.9 & 16.0 & -6.7 \\
\hline & $94 X-1$ & 10.1 & 79.7 & 10.1 & 37.7 & 58.7 & 3.6 & -26.4 \\
\hline & $109-1$ & 15.1 & 82.1 & 2.8 & 9.2 & 88.1 & 2.8 & 7.3 \\
\hline & $112-1$ & 18.1 & 75.7 & 6.2 & 37.9 & 53.7 & 8.5 & -29.1 \\
\hline \multirow[t]{10}{*}{ Midday } & $12-0$ & 52.0 & 47.0 & 0.9 & 58.7 & 40.1 & 1.1 & -14.6 \\
\hline & $12-1$ & 83.8 & 16.2 & 0.0 & 69.3 & 30.5 & 0.2 & 87.6 \\
\hline & $14-0$ & 13.8 & 74.9 & 11.2 & 11.9 & 74.6 & 13.5 & -0.4 \\
\hline & $14-1$ & 23.3 & 73.9 & 2.8 & 45.9 & 51.2 & 2.9 & -30.8 \\
\hline & 72-N/W & 6.8 & 62.1 & 31.1 & 6.5 & 58.9 & 34.6 & -5.2 \\
\hline & 72-E/S & 11.1 & 68.6 & 20.4 & 10.4 & 63.8 & 25.8 & -7.0 \\
\hline & $109-0$ & 5.0 & 89.4 & 5.6 & 6.1 & 87.2 & 6.7 & -2.5 \\
\hline & 109-1 & 13.4 & 81.6 & 5.0 & 11.5 & 84.6 & 3.9 & 3.6 \\
\hline & $112-0$ & 13.3 & 76.4 & 10.3 & 12.8 & 80.7 & 6.6 & 5.6 \\
\hline & $112-1$ & 17.2 & 79.9 & 2.9 & 24.3 & 71.1 & 4.5 & -10.9 \\
\hline \multirow[t]{7}{*}{ P.M. } & $12-0$ & 59.0 & 20.5 & 20.5 & 71.8 & 27.6 & 0.6 & 34.4 \\
\hline & $14-0$ & 9.7 & 77.5 & 12.9 & 9.1 & 73.5 & 17.4 & -5.2 \\
\hline & 72-N/W & 7.0 & 58.4 & 34.6 & 9.1 & 61.7 & 29.2 & 5.6 \\
\hline & 72-E/S & 2.8 & 65.9 & 31.3 & 10.9 & 48.8 & 40.3 & -25.9 \\
\hline & $94 X-0$ & 2.0 & 68.7 & 29.3 & 43.9 & 49.0 & 7.1 & -28.7 \\
\hline & $109-0$ & 11.2 & 82.5 & 6.3 & 12.6 & 81.1 & 6.3 & -1.7 \\
\hline & $112-0$ & 7.6 & 74.8 & 17.6 & 20.5 & 74.8 & 4.8 & 0.0 \\
\hline A.M. & All & 31.0 & 60.9 & 8.1 & 34.6 & 58.5 & 6.9 & -3.8 \\
\hline Midday & All & 22.6 & 67.1 & 10.3 & 24.5 & 63.9 & 11.6 & -4.7 \\
\hline P.M. & All & 12.2 & 66.0 & 21.8 & 22.1 & 61.3 & 16.6 & -7.2 \\
\hline Total & All & 22.2 & 65.9 & 11.9 & 25.7 & 62.6 & 11.7 & -5.0 \\
\hline
\end{tabular}


TABLE 7 Headway Analysis

\begin{tabular}{|c|c|c|c|c|c|c|c|c|c|}
\hline \multirow[b]{2}{*}{ TOD } & \multirow[b]{2}{*}{ Segment } & \multicolumn{3}{|c|}{$\begin{array}{l}\text { Mean Headway } \\
\text { (min.) }\end{array}$} & \multicolumn{2}{|c|}{$\begin{array}{l}\text { Var. Headway } \\
\text { (min.) }\end{array}$} & \multicolumn{3}{|c|}{$\begin{array}{l}\text { Excess Wait } \\
\quad \text { (min.) }\end{array}$} \\
\hline & & $\mathrm{N}$ & Pre & Post & Pre & Post & Pre & Post & \% Diff. \\
\hline \multirow[t]{7}{*}{ A.M. } & $12-1$ & 83 & 15.6 & 16.3 & 10.4 & 28.2 & 0.33 & 0.72 & 117.1 \\
\hline & $14-1$ & 233 & 5.1 & 5.5 & 5.7 & 8.6 & 0.31 & 0.58 & 86.1 \\
\hline & 72-N/W & 193 & 9.6 & 11.4 & 19.2 & 58.8 & 0.85 & 0.86 & 1.1 \\
\hline & 72-E/S & 179 & 9.2 & 11.4 & 9.6 & 55.4 & 0.42 & 0.65 & 54.7 \\
\hline & $94 X-1$ & 101 & 10.3 & 10.1 & 19.6 & 20.9 & 0.71 & 0.31 & -55.9 \\
\hline & $109-1$ & 202 & 9.5 & 10.0 & 16.9 & 17.2 & 0.48 & 0.64 & 33.5 \\
\hline & $112-1$ & 160 & 12.3 & 10.3 & 18.4 & 22.7 & 0.45 & 0.58 & 28.4 \\
\hline \multirow[t]{10}{*}{ Midday } & $12-0$ & 253 & 16.2 & 16.3 & 27.2 & 51.6 & 0.82 & 1.59 & 93.1 \\
\hline & $12-1$ & 222 & 15.7 & 15.4 & 23.2 & 27.3 & 0.41 & 0.59 & 44.6 \\
\hline & $14-0$ & 556 & 11.4 & 11.8 & 12.5 & 14.5 & 0.36 & 0.40 & 11.3 \\
\hline & $14-1$ & 366 & 11.7 & 12.0 & 12.4 & 17.3 & 0.34 & 0.59 & 71.4 \\
\hline & 72-N/W & 767 & 8.8 & 10.3 & 20.1 & 38.6 & 0.80 & 0.90 & 12.4 \\
\hline & 72-E/S & 742 & 8.9 & 10.1 & 23.0 & 31.2 & 1.15 & 0.98 & -14.8 \\
\hline & $109-0$ & 455 & 13.8 & 14.3 & 13.0 & 30.7 & 0.36 & 0.56 & 53.0 \\
\hline & $109-1$ & 509 & 13.6 & 14.6 & 32.3 & 38.6 & 1.64 & 0.99 & -39.6 \\
\hline & $112-0$ & 436 & 16.3 & 14.4 & 44.8 & 21.9 & 0.69 & 0.43 & -37.6 \\
\hline & $112-1$ & 446 & 15.6 & 14.5 & 21.5 & 23.7 & 0.52 & 0.62 & 17.9 \\
\hline \multirow[t]{7}{*}{ P.M. } & $12-0$ & 109 & 15.6 & 15.6 & 25.2 & 31.3 & 0.71 & 0.77 & 7.4 \\
\hline & $14-0$ & 331 & 5.4 & 5.6 & 8.3 & 7.0 & 0.65 & 0.54 & -17.0 \\
\hline & 72-N/W & 238 & 8.0 & 8.9 & 13.6 & 22.0 & 0.77 & 0.85 & 10.5 \\
\hline & 72-E/S & 200 & 8.0 & 10.0 & 25.2 & 34.4 & 1.44 & 1.14 & -20.9 \\
\hline & $94 X-0$ & 251 & 12.5 & 12.3 & 26.3 & 25.6 & 0.88 & 1.03 & 17.1 \\
\hline & $109-0$ & 122 & 10.2 & 8.2 & 15.0 & 20.2 & 0.50 & 0.92 & 86.2 \\
\hline & $112-0$ & 194 & 11.5 & 10.5 & 34.4 & 16.3 & 1.36 & 0.54 & -60.4 \\
\hline A.M. & All & 1,151 & 9.5 & 10.0 & $13.9^{\mathrm{a}}$ & $30.3^{\mathrm{a}}$ & 0.53 & 0.69 & 29.1 \\
\hline Midday & All & 4,752 & 12.4 & 12.7 & $22.6^{\mathrm{a}}$ & $29.5^{\mathrm{a}}$ & 0.83 & 0.80 & -4.0 \\
\hline P.M. & All & 1,445 & 9.4 & 9.6 & $20.0^{\mathrm{a}}$ & $20.7^{\mathrm{a}}$ & 0.98 & 0.84 & -14.3 \\
\hline Total & All & 7,348 & 11.3 & 11.7 & $20.7^{\mathrm{a}}$ & $27.9^{\mathrm{a}}$ & 0.82 & 0.80 & -2.8 \\
\hline
\end{tabular}

(a) Denotes weighted total (weighted by the number of trips for each segment in time period) 


\section{TABLE 8 Regression Analysis- Variable Description}

Variable

RTA

RTS

STOPS

LIFTS

EXPER

LTETRM

PERIOD

TOD2

TOD4
Description

Actual run time (minutes)- dependent variable Scheduled run time (minutes)

Stops made (actual)

Lift operations (actual)

Operator years of service (years)

Delay at origin terminal (minutes)

Period $(1=$ post TSP implementation, $0=$ pre TSP implementation $)$

A.M. peak time period $(1=$ true, $0=$ otherwise $)$

P.M. peak time period $(1=$ true, $0=$ otherwise $)$ 
TABLE 9 Regression Analysis- Descriptive Statistics

\begin{tabular}{lrrrrr} 
Variable & Mean & Std. Dev. & Variance & Min. & Max. \\
\hline RTA & 33.15 & 16.95 & 287.32 & 11.67 & 89.10 \\
RTS & 31.85 & 15.51 & 240.52 & 14.62 & 62.85 \\
STOPS & 26.05 & 15.11 & 228.41 & 1.00 & 85.00 \\
LIFTS & 0.18 & 0.55 & 0.31 & 0.00 & 5.00 \\
EXPER & 11.76 & 8.68 & 75.42 & 0.04 & 31.59 \\
LTETRM & 1.36 & 1.53 & 2.33 & -2.77 & 17.20 \\
PERIOD & 0.50 & 0.50 & 0.25 & 0.00 & 1.00 \\
TOD2 & 0.16 & 0.36 & 0.13 & 0.00 & 1.00 \\
TOD4 & 0.17 & 0.37 & 0.14 & 0.00 & 1.00 \\
\hline
\end{tabular}


TABLE 10 Regression Analysis- Results

\begin{tabular}{lrrrr} 
Variable & Coef. & Std. Error & T-Ratio & Seconds $^{1}$ \\
\hline RTS & 0.89 & 0.00 & 292.90 & 53.26 \\
STOPS & 0.20 & 0.00 & 64.77 & 12.10 \\
LIFTS & 1.09 & 0.04 & 27.24 & 65.11 \\
EXPER & -0.03 & 0.00 & -10.96 & -1.71 \\
LTETRM & -0.05 & 0.01 & -3.52 & -2.99 \\
PERIOD & -0.24 & 0.04 & -5.52 & -14.20 \\
TOD2 & -0.74 & 0.06 & -12.17 & -44.35 \\
TOD4 & 1.17 & 0.06 & 19.06 & 70.43 \\
CONSTANT & -0.14 & 0.07 & -1.99 & -8.35 \\
\hline N & 18,132 &. &. &. \\
R2 ADJ. & 0.971 &. &. &. \\
\hline
\end{tabular}

(1) Seconds = beta coefficient converted to seconds Dependent variable is actual run time in minutes 
TABLE 11 Summary: Performance Measures by Analysis Segment

\begin{tabular}{|c|c|c|c|c|c|c|c|c|c|}
\hline TOD & Segment & $\begin{array}{c}\text { Mean } \\
\text { Actual } \\
\text { Run } \\
\text { Time }\end{array}$ & $\begin{array}{c}\text { Var. } \\
\text { Actual } \\
\text { Run } \\
\text { Time }\end{array}$ & $\begin{array}{c}\text { Sched. } \\
\text { Run } \\
\text { Time } \\
\text { Savings }\end{array}$ & $\begin{array}{l}\text { Recov./ } \\
\text { Lay. } \\
\text { Time } \\
\text { Savings }\end{array}$ & OTP & $\begin{array}{c}\text { Mean } \\
\text { Actual } \\
\text { Hwy. }\end{array}$ & $\begin{array}{l}\text { Var. } \\
\text { Actual } \\
\text { Hwy. }\end{array}$ & $\begin{array}{c}\text { Excess } \\
\text { Wait }\end{array}$ \\
\hline \multirow[t]{7}{*}{ A.M. } & $12-1$ & - & + & - & + & + & - & - & - \\
\hline & $14-1$ & + & + & - & - & + & - & - & - \\
\hline & 72-N/W & + & - & + & + & + & - & - & - \\
\hline & 72-E/S & - & - & - & - & - & - & - & - \\
\hline & $94 \mathrm{X}-1$ & - & + & - & + & - & + & - & + \\
\hline & $109-1$ & - & - & - & - & + & - & - & - \\
\hline & $112-1$ & - & - & - & - & - & + & - & - \\
\hline \multirow[t]{10}{*}{ Midday } & $12-0$ & + & - & + & - & - & - & - & - \\
\hline & $12-1$ & - & - & - & - & + & + & - & - \\
\hline & $14-0$ & - & - & - & - & - & - & - & - \\
\hline & $14-1$ & + & + & + & - & - & - & - & - \\
\hline & 72-N/W & - & + & - & + & - & - & - & - \\
\hline & 72-E/S & - & - & - & - & - & - & - & + \\
\hline & 109-0 & + & - & + & - & - & - & - & - \\
\hline & $109-1$ & - & + & - & + & + & - & - & + \\
\hline & $112-0$ & + & + & + & + & + & + & + & + \\
\hline & $112-1$ & - & - & - & - & - & + & - & - \\
\hline \multirow[t]{7}{*}{ P.M. } & $12-0$ & + & + & + & + & + & + & - & - \\
\hline & $14-0$ & - & - & + & - & - & - & + & + \\
\hline & 72-N/W & + & + & + & + & + & - & - & - \\
\hline & 72-E/S & - & - & - & - & & - & - & + \\
\hline & $94 X-0$ & + & + & + & + & - & + & + & - \\
\hline & $109-0$ & + & - & + & - & - & + & - & - \\
\hline & $112-0$ & + & + & + & + & + & + & + & + \\
\hline Total & All & + & + & + & + & - & - & - & + \\
\hline
\end{tabular}

$(+)$ positive (ideal direction of performance measure)

(-) negative (opposite of ideal direction of performance measure) 
TABLE 12 Summary: Percentage of Segments Showing Improvements by Route

\begin{tabular}{|c|c|c|c|c|c|c|c|c|c|}
\hline Segment & $\begin{array}{l}\text { No. } \\
\text { Segs. }\end{array}$ & $\begin{array}{c}\text { Mean } \\
\text { Actual } \\
\text { Run } \\
\text { Time } \\
(\%) \\
\end{array}$ & $\begin{array}{l}\text { Var. } \\
\text { Actual } \\
\text { Run } \\
\text { Time } \\
(\%) \\
\end{array}$ & $\begin{array}{c}\text { Sched. } \\
\text { Run } \\
\text { Time } \\
\text { Savings } \\
(\%)\end{array}$ & $\begin{array}{l}\text { Recov./ } \\
\text { Lay. } \\
\text { Time } \\
\text { Savings } \\
(\%) \\
\end{array}$ & $\begin{array}{l}\text { OTP } \\
(\%)\end{array}$ & $\begin{array}{c}\text { Mean } \\
\text { Hwy. } \\
(\%)\end{array}$ & $\begin{array}{c}\text { Var. } \\
\text { Hwy. } \\
(\%)\end{array}$ & $\begin{array}{c}\text { Excess } \\
\text { Wait } \\
(\%)\end{array}$ \\
\hline 12 & 4 & 50.0 & 50.0 & 50.0 & 50.0 & 75.0 & 50.0 & 0.0 & 0.0 \\
\hline 14 & 4 & 50.0 & 50.0 & 50.0 & 0.0 & 25.0 & 0.0 & 25.0 & 25.0 \\
\hline 72 & 6 & 33.3 & 33.3 & 33.3 & 50.0 & 33.3 & 0.0 & 0.0 & 33.3 \\
\hline $94 \mathrm{X}$ & 2 & 50.0 & 100.0 & 50.0 & 100.0 & 0.0 & 100.0 & 50.0 & 50.0 \\
\hline 109 & 4 & 50.0 & 25.0 & 50.0 & 25.0 & 50.0 & 25.0 & 0.0 & 25.0 \\
\hline 112 & 4 & 50.0 & 50.0 & 50.0 & 50.0 & 50.0 & 100.0 & 50.0 & 50.0 \\
\hline Total & 24 & 45.8 & 45.8 & 45.8 & 41.7 & 41.7 & 37.5 & 16.7 & 29.2 \\
\hline
\end{tabular}


TABLE 13 Summary: Percentage of Segments Showing Improvements by Time of Day

\begin{tabular}{|c|c|c|c|c|c|c|c|c|c|}
\hline $\begin{array}{l}\text { Time } \\
\text { Period }\end{array}$ & $\begin{array}{l}\text { No. } \\
\text { Segs. }\end{array}$ & $\begin{array}{c}\text { Mean } \\
\text { Actual } \\
\text { Run } \\
\text { Time } \\
(\%)^{1}\end{array}$ & $\begin{array}{c}\text { Var. } \\
\text { Actual } \\
\text { Run } \\
\text { Time } \\
(\%) \\
\end{array}$ & $\begin{array}{c}\text { Sched. } \\
\text { Run } \\
\text { Time } \\
\text { Savings } \\
(\%) \\
\end{array}$ & $\begin{array}{c}\text { Recov./ } \\
\text { Lay. } \\
\text { Time } \\
\text { Savings } \\
(\%) \\
\end{array}$ & $\begin{array}{l}\text { OTP } \\
(\%)\end{array}$ & $\begin{array}{l}\text { Mean } \\
\text { Hwy. } \\
(\%)\end{array}$ & $\begin{array}{c}\text { Var. } \\
\text { Hwy. } \\
(\%)\end{array}$ & $\begin{array}{c}\text { Excess - } \\
\text { Wait } \\
(\%) \\
\end{array}$ \\
\hline A.M. & 7 & 28.6 & 42.9 & 14.3 & 42.9 & 57.1 & 28.6 & 0.0 & 14.3 \\
\hline Midday & 14 & 28.6 & 28.6 & 28.6 & 21.4 & 21.4 & 21.4 & 7.1 & 21.4 \\
\hline P.M. & 7 & 71.4 & 57.1 & 85.7 & 57.1 & 42.9 & 57.1 & 42.9 & 42.9 \\
\hline Total & 24 & 45.8 & 45.8 & 45.8 & 41.7 & 41.7 & 37.5 & 16.7 & 29.2 \\
\hline
\end{tabular}




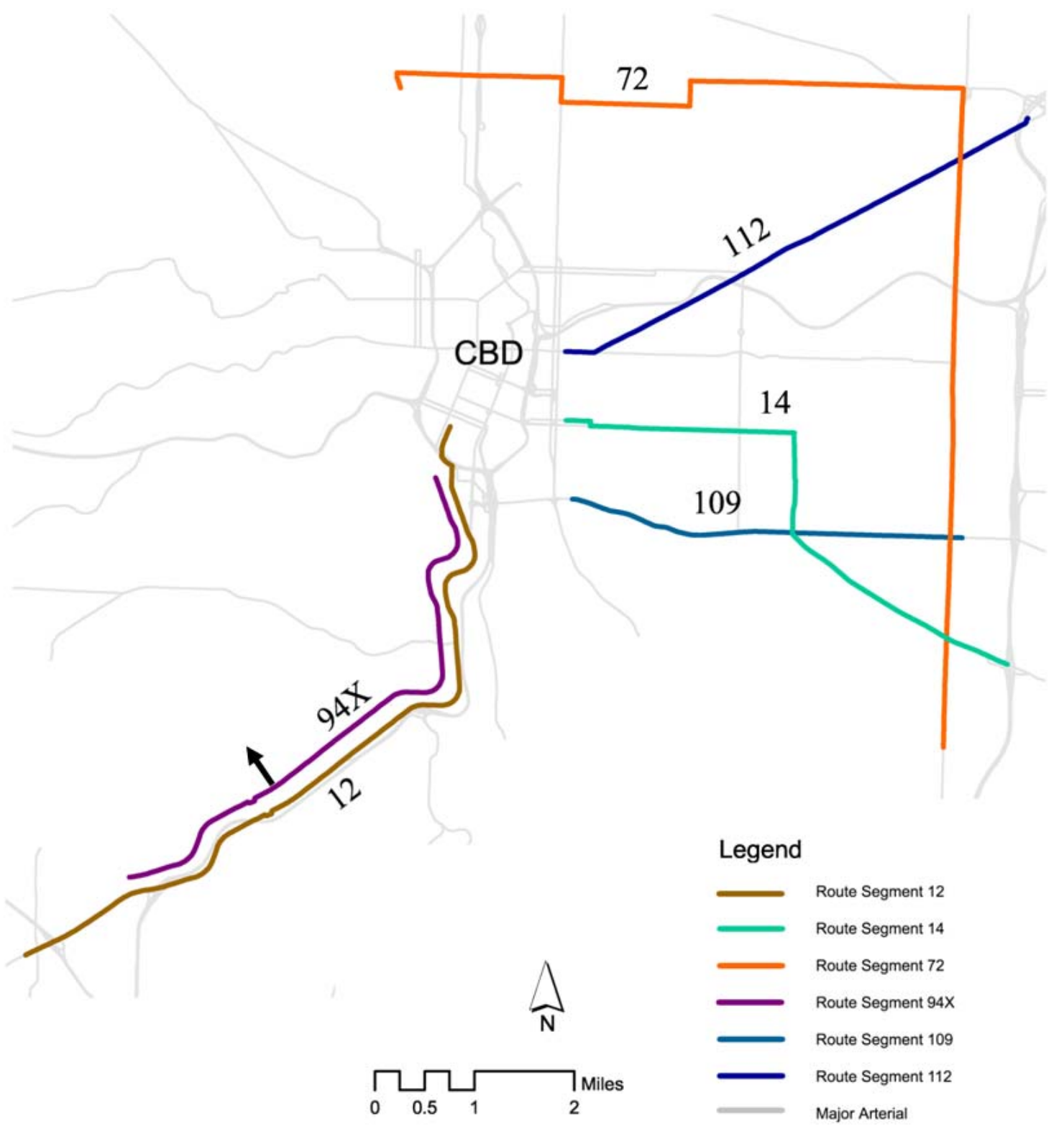

FIGURE 1 Study Area Map 


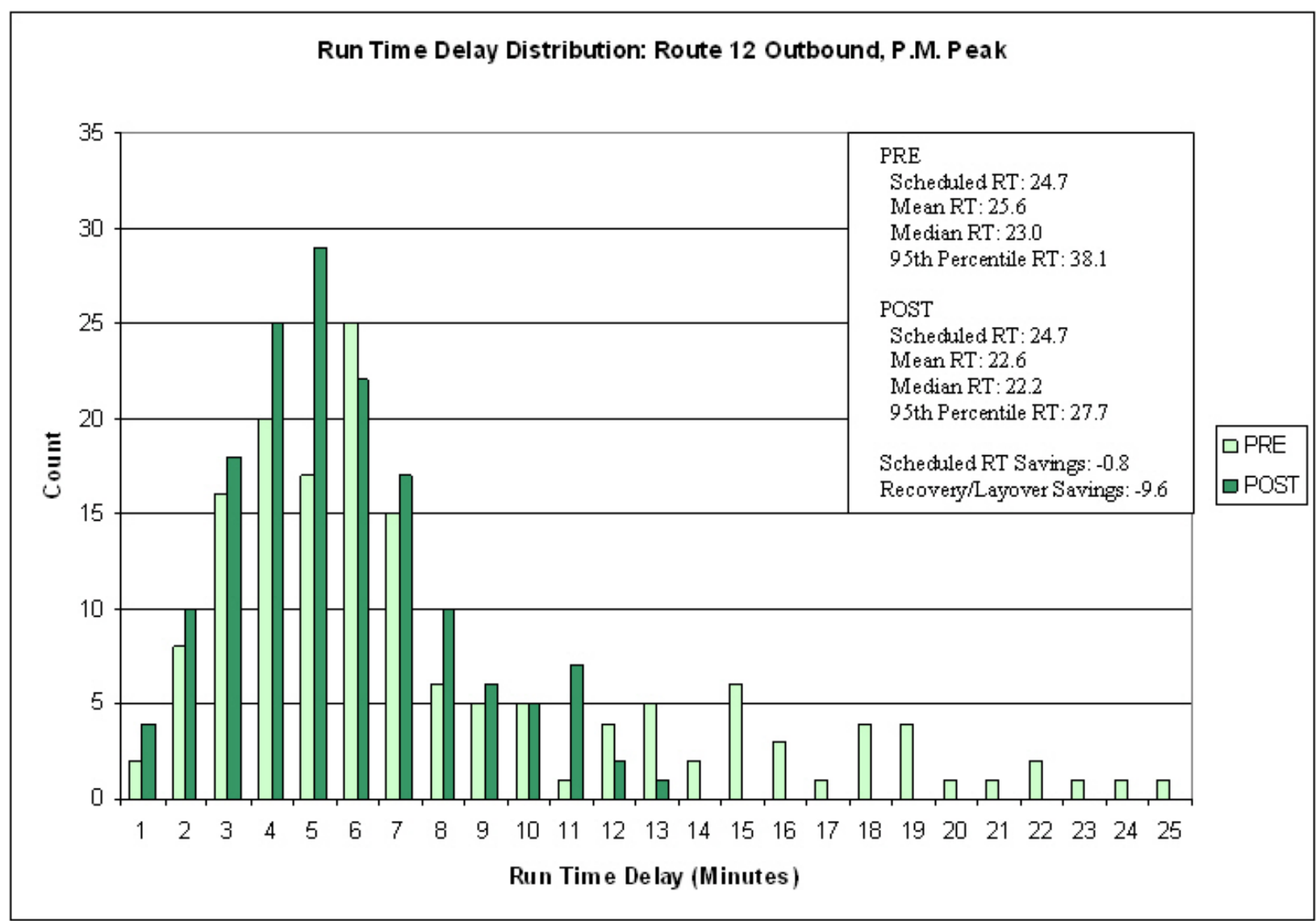

FIGURE 2 Running Time Delay Distribution 